\title{
Advocacy Strategies in Global Governance: Inside vs. Outside Lobbying
}

\author{
Lisa Maria Dellmuth and Jonas Tallberg \\ Stockholm University
}

\begin{abstract}
As political authority shifts to the global level, non-governmental organisations (NGOs) increasingly attempt to influence policy-making within international organisations (IOs). This article examines the nature and sources of NGOs' advocacy strategies in global governance. We advance a two-fold theoretical argument. First, NGO advocacy can be described in terms of inside and outside strategies, similar to interest group lobbying in American and European politics. Second, NGOs' chosen combination of inside and outside strategies can be explained by their organisational goals and membership base. Empirically, this argument is corroborated through a large-n analysis of original data from structured interviews with 303 NGO representatives active in relation to the United Nations (UN), complemented by 19 semistructured interviews with UN and state officials. The article's findings have implications for the theory and practice of NGO involvement in global governance.
\end{abstract}

\section{Keywords}

Advocacy, Organisational survey and interviews, United Nations, Global governance, NGOs 


\section{Acknowledgements}

An earlier version was presented at the 2016 Annual Conference of the American Political Science Association (APSA). We thank Beth Simmons, Björn Ljung, and the panel participants for helpful comments and suggestions. We thank Hans Agné and Andreas Duit for the collaboration on the data collection. Data and supplemental information necessary to reproduce the numerical results are available at the website of Lisa Maria Dellmuth at Stockholm University (www.lisadellmuth.se). The research for this article was funded by the European Research Council (Grant 200971-DII) and Riksbankens Jubileumsfond (Grant M2007-0399). 
As political authority has shifted from the national to the global level, non-governmental organisations (NGOs) have begun to devote extensive energy and resources to the task of influencing policy-making within international organisations (IOs). In the case of the United Nations (UN), more than 4,000 NGOs have sought and gained consultative status (UN, 2015), while 7,400 organisations, many of them NGOs, are now listed in the interest group register of the European Union (EU, 2015). Similarly, hundreds of NGOs regularly attend the ministerial meetings and conferences of IOs such as the World Trade Organization (WTO), the UN climate change negotiations and the World Bank (Hanegraaff et al., 2011; Uhre, 2014; World Bank, 2015).

In this article, we address NGOs' choice of lobbying strategies vis-à-vis IO policymakers. While NGOs increasingly engage with IOs, they vary in the advocacy strategies they adopt when seeking to influence policy-making. Whereas some NGOs primarily engage in direct lobbying of policy-makers, providing information and arguments, other NGOs mainly try to influence policy-makers indirectly, through mobilisation of public opinion. NGOs' strategy choice is an issue of intrinsic interest to research on advocacy and lobbying in International Relations (IR) and Comparative Politics (CP). Furthermore, as lobbying strategies are varyingly successful in influencing IO decision-making (Tallberg et al., 2015), and IOs are known to shape global political outcomes (Martin and Simmons 2012), questions about the patterns and causes of NGO strategies in global governance are of great importance both for researchers and practitioners.

NGOs' choice of lobbying strategies vis-à-vis IOs is a topic which so far has received limited systematic attention (Guldbrandsen and Andresen, 2004; Hadden, 2015; Hanegraaff et al., 2016). While there is a rich body of research on NGO advocacy in IR (e.g., Keck and Sikkink, 1998; O’Brien et al., 2000; Bob, 2009; Prakash and Gugerty, 2010; Carpenter, 2011; for overviews, see Risse, 2012; Stroup and Murdie, 2012), this literature has yet to explore the 
patterns and causes of lobbying strategies in interactions with IOs. Furthermore, strategy choice is a classic topic in interest group research in CP (e.g., Schlozman and Tierney, 1986; Kollman, 1998; Beyers, 2004; Binderkrantz, 2005; Dür and Mateo, 2013); however, this agenda has yet to be extended to lobbying in IOs.

We advance a two-fold argument about the nature and determinants of NGO lobbying in global governance, inspired by theories of interest group behaviour in the study of American and European politics. First, we argue that NGO advocacy in global governance can be conceptualised in terms of inside and outside lobbying. Inside lobbying refers to activities which aim to influence political outcomes through direct interaction with decision-makers, and outside lobbying to activities which aim to influence outcomes by putting pressure on decision-makers through the mobilisation of public opinion. Importantly, NGOs are not "insiders" or "outsiders," but can be expected to combine direct interaction with policymakers and mobilisation of public opinion in varying proportions.

Second, we argue that NGOs' chosen combination of lobbying strategies is a function of their goals and membership base. Conceptualising NGOs as strategic actors pursuing multiple objectives through IOs, we argue that NGOs primarily seeking political influence have more incentives to rely more extensively on inside strategies, and explain how this effect is moderated by the reliance of NGOs on membership contributions. When NGOs are dependent on membership funding, they should seek influence through outside strategies to a greater extent, since such strategies help to keep their supporters mobilised. NGOs which do not rely on membership funding do not face the same constraints and can therefore focus more intensively on inside lobbying. We contrast this argument with three prominent alternative explanations, privileging the resources of NGOs, the issue context in which they are active, and their access to IOs. 
Empirically, we corroborate this two-step argument using a novel dataset based on structured interviews among representatives of 303 randomly selected NGOs active in relation to the UN, complemented by 19 semi-structured elite interviews with $\mathrm{UN}$ and state officials (see list of interviews in the Appendix). Through a series of statistical analyses of the interview data, we advance on existing research on NGO advocacy, which is dominated by case studies of campaigns, individual NGOs and networks (for similar assessments, see Risse, 2012; Mitchell and Schmitz, 2014). The UN is particularly relevant to any inquiry of NGO advocacy as the foremost organisational hub in global governance with authority in multiple issue areas and a long history of interaction with NGOs.

\section{The Argument: Lobbying Strategies in Global Governance}

Our theoretical argument is in two parts. We first introduce the distinction between inside and outside strategies, and then present our privileged explanation of NGOs' choice of lobbying strategies, centered on organisational goals and membership.

\section{The Nature of Advocacy: Inside and Outside Strategies}

The influence strategies used by interest groups are a long-standing interest in American politics (e.g., Schlozman and Tierney, 1986; Hansen, 1991; Kollman, 1998) and have recently gained increasing attention in the European setting (e.g., Beyers, 2004; Kriesi et al., 2007; Dür and Mateo, 2013). Existing literature conventionally distinguishes between inside and outside strategies, where inside strategies are understood as influence tactics which involve direct interaction with decision-makers, and outside strategies as tactics aimed at influencing decision-makers indirectly through public-opinion mobilisation. Prominent inside tactics include meeting with decision-makers, offering policy expertise to decision-makers, and 
informing decision-makers about the views and needs of the constituencies which lobbyists represent. Prominent outside tactics include mobilising public opinion through news media, social media and public events such as campaigns and protests. Both strategies have been shown to require extensive resources (Binderkrantz, 2005; Dür and Mateo, 2013).

We argue that the distinction between inside and outside lobbying is useful for understanding the strategies of NGOs in global governance. First, NGOs, just as interest groups in American and European politics, are strategic actors who we can expect make informed choices about the strategies which best serve their interests. While there has been a tendency to view NGOs as constitutively different from interest groups, by emphasising their value-based orientation, we join contributions which question this assumption (e.g., Keck and Sikkink, 1998; Prakash and Gugerty, 2010; Mitchell and Schmitz, 2014).

Second, what is referred to as NGOs in IR has a large conceptual overlap with the standard definition of interest groups as organisations with autonomy from both government and parties which seek to influence public policy (compare Baumgartner and Leech, 1988; Risse, 2012). In addition, there is a substantial empirical overlap, since many groups are active at both the national and the global level, but are then typically referred to by different terms in the scholarly discourse (Bloodgood, 2010).

Third, existing research on NGOs points to multiple examples of influence tactics potentially classifiable as inside strategies, such as providing information on policy options and constituency interests (e.g., Betsill and Corell, 2008), or outside strategies, such as organising campaigns and protests (e.g., Della Porta and Tarrow, 2005; Hadden, 2015).

Fourth, while there are notable differences between global and domestic politics as strategic settings, such as the absence of a clear electoral connection in the former, there are important similarities as well. Like domestic governments, IOs demand information which cannot be sufficiently generated within, leading them to create opportunities for inside 
lobbying by societal interests in possession of this information (Tallberg et al. 2013). Similarly, like domestic politics, IO policy-making may be influenced by public opinion, most often through its effects on the positions of member state governments, suggesting why outside lobbying is relevant (Putnam 1988; Martin 2000).

Starting from the assumption that NGOs' strategy options and choice motives in global governance are not intrinsically different from those of interest groups in domestic or European politics, we expect that NGOs pursue combinations of inside and outside lobbying, rather than rely exclusively on the one or the other strategy. Research in the American and European context suggests that interest groups typically see inside and outside strategies as complementary rather than competing (e.g., Kollman 1998; Binderkrantz, 2008; Dür and Mateo, 2013). The choice of strategy is not binary, but one of combining tactics so as to maximise the chances of success, given limited resources. While it is sometimes assumed that all groups would have a preference for inside access to decision-makers (e.g., Grant, 2000), since this is seen as the more effective influence strategy, empirics suggests otherwise (Beyers, 2004; Kollman, 1998). One reason is the advantage of outside lobbying in demonstrating publicly that a group is actively working for a cause, making it easier to maintain and extend the membership (Binderkrantz, 2005; Dür and Mateo, 2013). Yet not all groups use the same combination of inside and outside strategies. This leads us to the second part of our argument.

\section{Determinants of Advocacy Strategies: Organisational Goals and Membership Base}

Our explanation of NGOs' choice of lobbying strategies privileges internal organisational factors. We advance the expectation that NGOs' chosen combination of inside and outside strategies will reflect the goals they pursue in an IO, conditioned by their funding structures. To begin with, we expect the goals pursued by NGOs within IOs to matter for their choice of 
advocacy strategy. While it is often assumed that groups are primarily focused on gaining political influence (Klüver, 2012), we expect NGOs to pursue multiple objectives within IOs, and the relative importance of these objectives to shape NGOs' choice of lobbying strategy (see also Dür and Mateo, 2013).

The often made assumption that NGOs primarily seek to influence policy is probably an artefact of the predominant focus in existing research on NGOs with an advocacy orientation, working to promote norms and values through pressure on domestic and international policymakers (e.g., Keck and Sikkink, 1998; O’Brien et al., 2000; Betsill and Corell, 2008). However, NGOs often pursue a broader repertoire of goals in global governance. Not all NGOs active in IOs are engaged in advocacy first and foremost, and even advocacy-oriented organisations may have other goals than influence. For instance, NGOs engaged in humanitarian aid, health and education have a service orientation, primarily cooperating with IOs in the implementation of policy programs. Other NGOs, such as those acting on behalf of indigenous communities, young people and women, have a representation orientation, primarily expressing the interests of their specific constituency vis-à-vis the IO. While NGOs with a service or representation orientation may engage in advocacy as well, political influence is likely to be a less important goal for these organisations than for advocacyoriented organisations. For service NGOs, securing funding for their operations is essential, while, for representation NGOs, identifying the implications of IO policy-making for their constituencies is crucial.

In addition, NGOs, irrespective of orientation, are likely to be concerned with one overarching goal, namely, organisational maintenance or survival (Cooley and Ron, 2002; Prakash and Gugerty, 2010). To remain active and relevant, NGOs need to secure funding, maintain commitment from their members or supporters, safeguard access to political arenas, and show that they make a difference. The specific concerns of NGOs related to organisational survival 
vary from case to case, yet the general implication is that NGOs may need to consider other objectives than political influence.

Our expectation is that NGOs should rely more on inside lobbying the more they aim to secure political influence through their engagement in IOs, relative to other goals. It is an established finding in existing research, and a widespread perception among practitioners, that inside lobbying is more effective for political influence than outside lobbying (e.g., Grant, 2000; Tallberg et al. 2015). If political influence was the only goal of NGOs in IOs, then inside strategies would likely dominate NGOs' lobbying efforts. Yet, since other goals may be better served through outside strategies, we would expect variation in the relative importance of political influence to shape NGOs' chosen combination of strategies. Hence, we hypothesise:

Hypothesis 1: The more NGOs seek political influence in an IO, the more they rely on inside strategies relative to outside strategies.

Furthermore, we expect the membership base of NGOs to matter for their choice of lobbying strategy. More precisely, we expect the dependency of NGOs on external funding by members to matter for their strategy choice. The most important distinction in our view is that between organisations dependent on contributions from their members or supporters (membership funded) and NGOs organised in ways which make them less or not at all dependent on such contributions (non-membership funded). Our focus on the funding dimension of NGOs' organisational structures draws inspiration from research privileging organisational characteristics as predictors for domestic interest group strategies (Walker 1983; Schlozman and Tierney, 1986; Beyers, 2004; Binderkrantz, 2008; Dür and Mateo, 
2013; Hanegraaff et al., 2016) and research on the political economy of NGO mobilisation (Cooley and Ron, 2002; Prakash and Gugerty, 2010).

Examples of membership-funded organisations in our dataset are: Fundacíon Intervida (EDUCO), whose donors are primarily individual citizens; the World Farmers' Organisation (WFO), whose members are national and regional farmers' organisations; and the Green Asia Network, whose membership consists of an array of professional networks and NGOs, such as foundations and research institutes. Examples of organisations which are not membership funded are: the Sasakawa Peace Foundation, which relies on investment returns; the Norwegian Refugee Council (NRC), whose work is financed by several European and North American governments, EU institutions and UN agencies; and the Rutgers World Population Foundation, which is mainly funded by the Dutch government.

As they confront the choice between inside and outside lobbying, membership- and non-membership funded NGOs face distinctly different incentives, even when both seek political influence. While non-membership-funded NGOs can focus on maximising the potential for political influence through inside lobbying, membership-funded NGOs need to consider two objectives at the same time: influencing policy and securing their membership base. The balancing of these objectives will lead membership-funded NGOs to rely relatively more on outside strategies, which best serve the goal of maintaining the financial support of their members and supporters. In this view, "indirect strategies...are not mere fall-back options for groups excluded from privileged access. Rather, they are chosen because they are instrumental in demonstrating to members and potential members that the group is working to promote group goals" (Binderkrantz, 2005, p. 698). We expect NGOs' funding structure to condition the effect of goals on the choice of lobbying strategy. The pursuit of influence should lead non-membership funded NGOs to rely more intensively on inside lobbying than 
membership-funded NGOs, who have stronger incentives to engage in outside lobbying as well. Hence, we hypothesise:

Hypothesis 2: The relationship between the goal of political influence and reliance on inside strategies relative to outside strategies (Hypothesis 1) should be stronger among NGOs which do not rely on membership funds.

\section{Alternative Explanations}

Our principal argument suggests that organisational goals and funding structure matter. However, previous literature suggests three main alternative explanations for NGOs' strategy choice. The first posits that resource-rich groups rely more extensively on inside lobbying than groups with few resources. Some assume that interest groups gain access to decisionmakers when they have informational resources that decision-makers demand (Hansen, 1991); if so, then groups rich in specialised information are in a more favourable position to engage in inside lobbying (Binderkrantz, 2008). Others emphasise that only groups wellendowed in terms of financial resources can afford to engage in inside lobbying, since direct contacts with decision-makers pose high demands on staff and time (Grant, 2000; Dür and Mateo, 2013). While poorer groups recognise the advantages of inside lobbying for political influence, they are forced to rely more extensively on the cheaper option of outside lobbying - the "strategy of the weak" (Grant, 2000).

Second, NGOs' choice of lobbying strategy may be a product of their access to decision-makers. NGOs' access to IOs varies considerably (Tallberg et al., 2013). This pattern mirrors the institutional conditions at the domestic level, with corporatist systems concentrating influence opportunities among a limited number of actors, and pluralist systems being less discriminatory (Schmitter and Lembruch, 1979). Such variation in access shapes 
interest groups' choice of strategy by inviting some to interact with decision-makers, while barring or discouraging others (Binderkrantz, 2005, p. 697; Kriesi et al., 2007, pp. 67-68). In this respect, access may be formal, such as the right to speak at official meetings, or informal, such as practices of engagement with IO staff.

A third alternative explanation suggests that the issue context may matter for NGOs' chosen combination of inside and outside strategies (Dür and Mateo, 2013). Advocacy groups may rely more extensively on outside lobbying when a policy area involves high levels of political conflict. When issues are highly salient, it is relatively easier to mobilise public opinion and therefore more rewarding to engage in outside tactics (Keck and Sikkink, 1998, p. 27; Hanegraaff et al., 2016). Moreover, there is a higher likelihood that inside lobbying will be met by counter-mobilisation from opposing groups when issues are politically contentious, reducing the expected effectiveness of this strategy in relation to its costs (Binderkrantz, 2005, p. 698). A common way of distinguishing between issues of varying salience is to differentiate between policy areas which are predominantly redistributive or regulatory in orientation (Lowi, 1964). Redistributive policies in IOs involve transfers of resources from one group to another and tend to be highly politicised because of their transparent implications for costs and benefits. Regulatory policies in IOs specify actions which all actors should either take or refrain from and are therefore less overtly conflictual, even if such common standards often impact gains distribution as well (Rittberger et al., 2012, pp. 120123).

\section{Interviews with NGO Representatives: Sample Selection}

To gather data suitable for mapping and explaining variation in NGOs' advocacy strategies, we conducted telephone interviews with a random sample of NGOs active with a view to UN policy-making between December 2011 and July 2012. The interview approach has three 
major advantages for our purposes. First, it allows us to collect data on the characteristics of NGOs, such as resource endowment, influence tactics and policy orientation. Second, it enables us to engage in a systematic and comparative analysis of the strategies of a large number of NGOs involved in different institutional and policy contexts. Third, by relying on interviews rather than web-coding, we can reach small NGOs which do not have a web presence.

The interviews focused on NGOs whose activities relate to the five main bodies of the UN: the General Assembly, the Security Council, the Economic and Social Committee, the International Court of Justice and the Secretariat, as well as all their subsidiary bodies. The choice of the UN was informed by several considerations. First, the UN is a multi-issue IO with internal variation in access rules, which permits us to examine NGO strategies across different issue areas and institutional contexts within the same organisational framework. Second, we could expect the UN as an organisational context not to bias against either inside or outside strategies, since the IO has a long history of interactions with NGOs, but is also very visible and often the target of public campaigns. Third, the UN is of particular empirical relevance as the foremost organisational hub in global governance.

The sample of NGOs was drawn to be representative for the NGO population active in relation to the UN. The NGO population was compiled for 2011 based on two sampling frames: (1) a list of accredited NGOs (UN, 2011), and (2) a list of NGOs which are not accredited, but indicate an interest in the UN in the Yearbook of International Organisations Online (Union of International Associations, 2011). ${ }^{1}$ Since the bar for NGOs to get accreditation to the UN is quite low (compare UN ECOSOC Resolution 1996/31), the population included in the first sampling frame includes a diverse set of organisations which vary in terms of type, geographical origin and resource endowment. By also including NGOs

\footnotetext{
${ }^{1}$ Where email addresses were not available in the sampling frames, we relied on NGOs' homepages for contact details.
} 
which are not accredited, we make sure that our sample is not limited to NGOs which all enjoy a basic level of institutionalised access, which may affect the likelihood of engaging in inside or outside lobbying. As individuals affiliated with or employed in accredited NGOs may be better positioned to answer questions about their interactions with the UN, it is an advantage that the final sample includes a larger number of accredited NGOs than nonaccredited NGOs.

This strategy yielded two sampling frames which together consist of a total population of 1836 NGOs, of which about 83 percent $(\mathrm{N}=316)$ were accredited to the UN. No NGOs appeared in both frames. After merging the two frames, we drew an unequal probability sample, whereby we assign a higher probability to accredited organisations to get selected into the sample, since we suspect those organisations to be more frequently active with a view to UN policy-making, leading to higher expertise and thus to more valid answers. ${ }^{2}$ This sampling strategy yielded a sample of 306 organisations, for which valid telephone numbers were available in the sampling frames or on the NGOs' homepages in 303 cases.

For the purpose of the telephone interviews among these 303 NGOs, we sought to identify the person who is most competent to answer questions about the NGO's advocacy work, typically a person in charge with liaison work. To this end, we contacted the secretariats of the organisations in advance by phone, providing information about the research project and the interviews and requesting an interview with the most knowledgeable person about an NGO's advocacy vis-à-vis the UN. More than half of the respondents had worked in their organisation for more than 10 years, increasing our confidence in the validity of the data. The

\footnotetext{
${ }^{2}$ To pre-test the questionnaire and to get an estimation of the response rate for the main field phase, we first conducted an online survey among an unequal probability sample as described above of 1006 of the 1836 NGOs. Accredited NGOs had a 60 percent chance to get selected into the sample, whereby non-accredited NGOs had a 30 percent chance. The pre-test yielded a response rate of about 30 percent. For the main field phase, we expected a higher response rate given that the main survey would be conducted by phone. To receive data for a sample that ensures enough statistical power to perform regression analysis, we drew an unequal probability sample among the remaining 830 NGOs, again with a 30 percent difference between NGOs in the two frames in terms of their chance of getting selected into the sample. Accredited NGOs had a 45 percent chance, while non-accredited NGOs had a 15 percent chance.
} 
questionnaire contained questions about an NGO's characteristics, opportunities for involvement in UN bodies and influence tactics. We asked NGO representatives to answer these questions with a view to the UN body they are most involved in, assuming that respondents know most about that body and will therefore give more valid answers.

Of the 303 NGOs in the sample, 224 completed their questionnaires, amounting to a completion rate of 74 percent. Of the completed questionnaires, 87 percent were from accredited NGOs. Since we expected non-accredited NGOs to be less likely to respond given a potentially lower interest in our interviews, non-accredited NGOs were given a greater probability to be selected into the sample than accredited NGOs. We calculated base weights for each sampling unit which reflect an NGO's probability of being selected into the sample, being calculated as the reciprocal of the probability of selection. We run all analyses using weighted data to correct for unequal selection probabilities and to make inferences about both accredited and non-accredited organisations.

Our completion rate is very high compared to response or completion rates achieved in studies of interest groups at the domestic and European levels (compare Dür and Mateo, 2013). While the frame population, sample and ultimate pool of respondents included more NGOs with accreditation than without, we expect the risk of a selection bias in favour of NGOs more inclined to use an inside strategy to be relatively limited. ${ }^{3}$ Non-accredited NGOs are not exclusively dependent on an outside strategy, since they may lobby policy-makers informally, just as interest groups do in many domestic political systems. This is one reason why we use a measure of access which captures both formal and informal opportunities to engage with UN policy-makers. Likewise, accredited NGOs do not only rely on an inside

\footnotetext{
${ }^{3}$ This is suggested by a $t$-test revealing that the mean scores of accredited and non-accredited NGOs on the variable relative inside strategy are not statistically different from each other $(p=0.5339)$. Likewise, the mean scores of accredited and non-accredited NGOs on each of the items measuring how commonly NGOs use different lobbying tactics are not statistically different from each other ( $p$-values from 0.1534 to 0.8994 ).
} 
strategy, since an outside strategy has advantages in mobilising public-opinion pressure and demonstrating activity to members.

In the absence of a 100 percent response rate, we examine the possibility of nonresponse error, which may arise when non-respondents systematically differ from respondents with regard to characteristics which are relevant to the object of inquiry. Given that NGOs' lobbying strategy and resource endowment may be systematically related (compare Klüver, 2012), our main concern was that resource-poor NGOs, which often come from the global south (Friedman et al., 2005; Uhre, 2014), may be less likely to respond than resource-rich NGOs. ${ }^{4}$ However, using the total population of NGOs in the sampling frames, we see that poorer southern NGOs are not less likely to respond when compared to NGOs from the global north $(p=0.19){ }^{5}$ Using our NGO sample, Figure 1 illustrates that most NGOs in the sample are relatively small, with average values in all regions being close to the category of 11-30 staff members. ${ }^{6}$ Interestingly, those NGOs in our sample which come from the global south are not less resourceful than NGOs from the global north.

\section{[Figure 1 about here]}

\section{Empirical Results}

\section{Lobbying Tactics and Strategies in the UN}

\footnotetext{
${ }^{4}$ By global north we refer to all countries that score 0.8 or higher on the Human Development Index in 2014 (compare UNDP, 2014). Hence, the global south encompasses Asia and the Pacific, Latin America, North Africa and the Middle East, and sub-Saharan Africa.

${ }^{5}$ This analysis is based on information for 64 countries. For about 10 percent of the respondents, the country of origin is not available, as some NGOs do not have their headquarters in one particular country.

${ }^{6}$ In our survey, annual budget is an alternative measurement for NGO resources. Yet, since budget correlates highly with staff ( $r=0.751, N=264)$ and has close to 7 percent more missing values, we rely on the staff measure.
} 
We conceptualise strategies as the overall approaches taken by NGOs when pursuing political goals. Empirically, strategies can be observed as combinations of different tactics or activities (Binderkrantz, 2005, p. 696). In the interviews, we therefore asked respondents how common it is for their organisation to adopt different types of influence strategies, tapping inside and outside strategies, respectively. First, we asked them about the body in the UN their organisation is most involved in, letting them choose one of the five main bodies of the UN. They were then asked to indicate whether there was one main subsidiary body of the main body that they were particularly active in. For this purpose, we provided a list of all 116 immediate sub-bodies of the five main UN bodies. ${ }^{7}$ These two questions increase the validity of our data, as respondents are not asked to answer questions about the $\mathrm{UN}$ as a whole, but about the sub-body their organisation is most involved in.

The interviews reveal that most NGOs use both inside and outside tactics. About 70 percent of the NGOs make use of at least one outside and one inside tactic either commonly or very commonly. ${ }^{8}$ Among outside tactics, the mobilisation of public opinion through news or social media is common or very common among about 54 percent of the NGOs, whereas close to 50 percent use campaigns, protests and events commonly or very commonly. Among inside tactics, the most commonly used approach is the provision of information on represented NGO groups (about 80 percent), followed by the provision of policy information and interactions with UN or state representatives (about 70 percent). About half of the NGOs commonly interact with low- or mid-level staff in the UN, whereas about 30 percent of the NGOs interact with the UN top-level management. The least commonly used tactic is the provision of financial resources (about 15 percent). Contrary to common assumptions, these figures suggest that outside tactics are not "outsider" tactics, in the sense of being reserved for

\footnotetext{
${ }^{7}$ Online Appendix A provides a list of all sub-bodies. Table B1 in online Appendix B details the wording of the survey questions.

${ }^{8}$ Online Appendix Tables C1 and C2 show descriptive statistics and bivariate correlation coefficients for all variables introduced in this section.
} 
a specific group of peripheral and disadvantaged NGOs, but that most NGOs use both types of tactics in a complementary fashion.

While these tactics may be conceptually classified as belonging to either an inside or outside strategy, it is an empirical issue whether they coalesce into more overarching strategies in the behaviour of NGOs. To examine this, we perform a factor analysis of the seven tactics, which allows us to identify strategies in terms of unobserved latent constructs. More generally, factor analysis describes linear combinations of the variables which contain most of the information in the data and which then allow for meaningful interpretations of factors (see also Dür and Mateo, 2013). ${ }^{9}$ Using factor analysis as an exploratory technique, the results yield two factors which clearly capture the theoretical distinction between inside and outside strategies (see Table 1). ${ }^{10}$ Table 1 displays the results for the two factors. ${ }^{11}$ The first factor is formed by three components describing an outside strategy: mobilising public opinion through news media, social media, campaigns, protest and events. This factor explains almost 44 percent of the variation in lobbying tactics. The higher NGOs score on this factor, the more distinct their strategy to seek influence over UN policy-making through public-opinion mobilisation. The second factor explains about 16 percent of the variation in the data and reflects an inside strategy composed by the provision of resources, policy information and constituency information, as well as interaction with IO or state representatives. The higher an NGO's score on this factor, the more clearly it adopts an inside strategy of direct lobbying.

\footnotetext{
${ }^{9}$ More specifically, factor analysis describes a set of $q$ factors that linearly construct the $p$ original variables. The procedure can be expressed as follows: $y_{i j}=a_{i l} \boldsymbol{F}_{l j}+a_{i l} \boldsymbol{F}_{l j}+a_{i l} \boldsymbol{F}_{l j}+e_{i j}$, where $y_{i u}$ is the value of the $i$ th observation on the $j$ th variable, $a_{i k}$ is the $i$ th observation on the $k$ th common factor (factor loadings), $\boldsymbol{F}_{k j}$ are underlying factors, and $e_{i j}$ is the $j$ th variable's residual variate, representing the part of the observed variation that does not correspond to the two factors.

${ }^{10}$ Since some respondents chose the "Don't know" category when answering the question about their strategies, the number of observations drops from 224 to 182 .

${ }^{11}$ The analysis did not yield a third factor. We retain only those factors for which the eigenvalue was greater than 1, respectively (compare Guttman 1954). Figure C1 in the online Appendix depicts the eigenvalues for all factors.
} 


\section{[Table 1 about here]}

\section{Explaining Lobbying Strategies in the UN}

Next, we examine why NGOs vary in their chosen combinations of inside and outside strategies. For this purpose, we require a measure for the relative weight placed by NGOs on inside relative to outside strategies. To create such a measure, we proceed in two steps. First, we calculate the factor scores for the inside and outside factor solutions. These scores are composite variables providing information about an NGO's placement on the inside factor and outside factor, respectively. ${ }^{12}$ We checked the robustness of the factor scores by calculating additive indexes of inside and outside strategies by adding the respective tactics. The almost perfect correlations between the two factors and their respective additive indices are evidence of the robustness of these two factor scores (each $r=0.998 ; N=198) .{ }^{13}$

Second, we subtract the 'outside strategy' factor from the 'inside strategy' factor. As the two factors are both continuous and normally distributed with a mean close to zero (see Online Appendix Table C1), this new variable is also continuous and approximately normally distributed from -2.649 to 2.987 , with a mean close to zero. ${ }^{14}$ NGOs which score higher than zero on the variable relative inside strategy place relatively greater emphasis on inside strategies compared to the average NGO in the sample. Vice versa, NGOs scoring lower than zero place relatively greater emphasis on outside strategies compared to the average NGO in the sample. NGOs which place equal weight on inside and outside strategies have values on the relative inside strategy variable close to zero. In other words, at negative values of relative inside strategy, NGOs emphasise outside strategies more than inside strategies. The closer the values get to zero, the less pronounced do the outside strategy relative to the inside strategy

\footnotetext{
${ }^{12}$ More specifically, factor scores are not obtained through estimations but by calculating the product of factor loadings and observed values for each observation. We calculate them using the method suggested by Thomson (1951), which produces the smallest man squared error compared with other available methods.

${ }^{13}$ These indices have a Cronbach's $\alpha$ of 0.77 each.

${ }^{14}$ See Figure C2 in the online Appendix which depicts the distribution of relative inside strategy.
} 
become. The greater the positive values of relative inside strategy, the more pronounced do inside strategies become relative to outside strategies.

To exemplify, consider three of the NGOs which we used to illustrate our theoretical argument, which have different values on the relative inside strategy variable: the membership-funded EDUCO (score of -0.861) and the WFO (0.038), as well as the nonmembership funded Rutgers World Population Foundation (1.378). EDUCO adopts all outside tactics very commonly, whereas most inside tactics are only commonly used, leading to a negative score on relative inside strategy. WFO relies commonly or very commonly on all tactics except for one inside and one outside tactic, translating into a score very close to zero. Last, Rutgers, with a relatively high positive score, places more emphasis on inside tactics, all of which are used very commonly, except for the provision of information and expertise, which is used commonly. By contrast, tactics which involve mobilisation of public opinion are not used as commonly. ${ }^{15}$

To examine the hypotheses, we conduct a series of ordinary least squares (OLS) regression analyses using relative inside strategy as a dependent variable. ${ }^{16}$ Hypothesis 1 requires a measure for the degree to which NGOs seek political influence in an IO. To create such a measure, we use the responses to a question of how often an NGO pursues the goal of seeking influence over UN policy-making. NGOs could indicate if they never (1), rarely (2), often (3) or very often (4) pursued that goal. To test Hypothesis 2, we create a dummy, coded 1 if an NGO is a membership organisation and 0 if otherwise. The coding relies on a question about whether NGOs had received membership fees over the past two years. About 60 percent of the NGOs in the sample are membership organisations. Table 2 shows that NGOs have

\footnotetext{
${ }^{15}$ To increase our confidence of the validity of our measures, we cross-validate these sample organizations using information compiled from sources other than the survey. For EDUCO, we draw on the organization's homepages and a report by the research institute Centre for Services and Information on Disability (CSID) on child labour (see Khan 2015). Both sources emphasise EDUCO's public strategy and community work as strengths, corroborating EDUCO's negative score on relative inside strategy.

${ }^{16}$ Multicollinearity should not inflate the coefficient estimates, as the variance inflation factor did not exceed 1.
} 
different goals with their engagement towards the UN, and that membership organisations slightly less often seek political influence and slightly more often seek to enhance the visibility of their organisations - descriptive patterns which conform to our theoretical expectations.

To operationalise the three alternative explanations, we first use the number of staff members employed by an NGO on a full-time basis as a proxy for an NGO's resources. Second, we code a variable access using the responses to a question asking interviewees to rank their organisations' opportunities for involvement in the five main bodies (and all of their subsidiary bodies) in the UN. The answer categories range from no opportunities (1), few opportunities (2), some opportunities (3), to many opportunities (4). This variable captures both formal and informal access to decision-makers, as perceived by NGOs. Third, we create a variable regulatory policy, which is coded 1 if an interviewee indicated that her organisation is active in a regulatory policy area (trade, environmental policy, finance, health policy, human rights and security and defence) and 0 if an NGO is active in a distributive policy area (development and humanitarian aid).

\section{[Table 2 about here]}

The regression results strongly endorse the hypotheses, even when controlling for alternative explanations (see Table 3). To begin with, the coefficients of the variable seeking influence are positively significant in models 1 and 2, indicating that NGOs seeking political influence in the UN are more likely to lean towards inside strategies, corroborating Hypothesis 1 . To illustrate, the model predicts a score of about 0.40 on the relative inside strategy variable for an NGO seeking influence in the UN very often, suggesting an emphasis on inside strategy, all else equal. By contrast, an NGO which never seeks influence in the UN 
is predicted to score about -0.40 on the strategy variable, indicating a preference for outside lobbying. ${ }^{17}$ Given that the variable relative inside strategy ranges from approximately -2.9 to 2.9 , this represents a substantively meaningful effect. This finding suggests that NGOs expect inside lobbying to be more effective for political influence than outside lobbying, which is also the principal finding of research on the impact of alternative advocacy strategies (Grant, 2000; Tallberg et al., 2015).

\section{[Table 3 about here]}

To examine Hypothesis 2, models 3 and 4 include an interaction term between NGO goals and funding structure. The coefficient of the interaction term between seeking influence and membership organisation is statistically significant at the 5 percent level even if controlling for the alternative explanations (two-sided $p$-value of 0.074). Figure 2 plots the marginal effect of seeking influence on strategy choice, showing that it is statistically significant only among non-membership NGOs, but not among membership-based NGOs. By implication, unlike non-membership organisations, membership organisations do not rely more extensively on inside strategies the more they seek influence. This may be explained by the fact that outside strategies typically are more visible among members than inside strategies, helping membership organisations to gain visibility, improve recruitment and thereby secure organisational survival. In sum, this finding refines Hypothesis 1 , showing a combined effect of organisational goals and funding structure on strategy choice.

\section{[Figure 2 about here]}

\footnotetext{
${ }^{17}$ We used the program Clarify to interpret the statistically significant effects (Tomz et al., 2003).
} 
Among the alternative explanations, only access to decision-makers gains some support in the regression analysis. For example, an NGO with no opportunities for access to the UN has a score of about -0.35 on the relative inside strategy variable, indicating that such an NGO privileges outside strategies. By contrast, an NGO with many opportunities for access scores close to .20 , indicating a more pronounced inside strategy. The findings suggest that NGOs enjoying greater perceived access tend to rely more extensively on an inside strategy. What can explain the absence of effects of resources and regulatory policy? Resources might not matter since we focus on the more homogenous group of NGOs in global governance, compared to the broad spectrum of interests (of which NGOs are one) in studies of domestic and European lobbying. Further, those NGOs which make it to the global level may already have passed a threshold in terms of mobilisation which makes remaining variation in resources less decisive for strategy choice. Finally, campaign contributions may lack relevance in the international setting.

The absence of an effect of policy type suggests that the classic distinction between redistributive and regulatory policy does not have the same implications in global policymaking as in domestic. One explanation might be that NGOs do not let this difference influence their strategy choice, since redistributive policies are relatively rare internationally. Alternatively, regulatory policies in global governance such as trade and climate change agreements are highly politically contentious, challenging the idea that redistributive policies would be more conflictual.

\section{Robustness of the Results}

We conducted three further analyses. First, we assessed whether our findings could have been affected by item non-response. To this end, we imputed all independent variables used in the regression tables which have missing values. More specifically, we impute the variables 
seeking influence (1.4 percent missing values) and staff members (0.3 percent missing values) using chained equations. ${ }^{18}$ The regression results lead to the same inferences (see Table C3 in the online Appendix).

Second, we conducted a series of 19 semi-structured interviews with member state representatives and secretariat officials in the UN in July and August 2012. These officials were asked similar questions about the goals and strategies pursued by NGOs in the UN body they are most involved in and given the opportunity to elaborate on their response. The interviews corroborate two important parts of our argument, namely that (1) NGOs engage more extensively in outside lobbying than what a pure interest in influence would dictate, and (2) NGOs typically pursue many parallel goals in the UN, of which funding is one. Several respondents indicate that NGOs often rely extensively on the outside strategy of mobilising public opinion through news media, social media and campaigns, while they themselves think that NGOs should engage more directly with state and UN representatives if they want to be successful in influencing policy (interviews 1, 2, 3, 4 and 5). In addition, state and UN representatives alike consider NGOs to be driven by multiple goals in the UN, where influence is only one, albeit often important. Several respondents highlight visibility and funding as central alternative objectives, often linking the two (interviews 1, 6, 7, 8, 9, 10 and 11). A UN official with long-term experience of NGOs from ECOSOC specifically emphasises "visibility that leads to funding" as the crucial goal (interview 8), and a Dutch state representative underlines the ambition "to enhance the visibility with an aim to raise funds" (interview 6).

Third, NGOs from the global south have been shown to have less access to IOs and may therefore be more prone to engage in outside strategies (compare Friedman et al., 2005;

\footnotetext{
${ }^{18}$ We tested whether the data are missing at random in the sense of Rubin (1976). First, we code a variable missing that equals 1 if NGOs takes on missing values on one or more variables and 0 if otherwise. The variable missing was then used as a dependent variable in a logistic regression, testing whether the other variables included in the analyses are systematically related to missing. Since the coefficients of the covariates were not statistically significant, we can reasonably assume that the MAR assumption holds.
} 
Hanegraaff et al., 2011; Uhre 2014). In our sample, 63 percent of the NGOs have their headquarters in the global north, that is, in a country which has a Human Development Index of 0.8 or higher in 2014 (see Figure C3 in the online Appendix; see also Tallberg et al., 2015). We replicate all models in Table 3 by controlling for NGOs' geographical background using region fixed effects. Our results remain robust (see Table C4 in the online Appendix).

Finally, we include a dichotomous variable in the models in Table 3 indicating whether an NGO is accredited to the UN (1) or not (0). We seek to test whether accreditation explains part of the variation in strategy choice. However, this variable is not statistically significant and all results remain robust to this change in model specification (see Table C5 in the online Appendix).

\section{Conclusion}

As IOs have gained in political authority, NGOs have increasingly mobilised to influence global policy-making. In this article, we have theorised and empirically assessed NGOs' choice of lobbying strategies vis-à-vis IO policy-makers. Our central findings from the UN are three-fold and suggest important similarities and differences in the lobbying strategies of international NGOs and domestic interest groups.

First, we have shown that the distinction between inside and outside strategies well captures the lobbying activities of NGOs in relation to the UN. On the one hand, they employ an inside strategy, providing policy information, communicating stakeholder interests and interacting with IO and state representatives. On the other hand, they follow an outside strategy, mobilising political leverage through news media, social media and public events. However, this does not mean that NGOs pursue a strategy of either or. Rather, it is a question of NGOs combining inside and outside tactics in the ways which best favour their interests. Importantly, outside tactics are not reserved for "outsiders" in the sense of marginalised 
NGOs. Recent research on NGOs in other global governance settings indicates that this pattern holds beyond UN as well (Hadden, 2015; Tallberg et al., 2015; Hanegraaff et al., 2016).

Second, we have demonstrated that NGOs' choice of lobbying strategy is determined by a combination of three factors, known to shape the strategies of domestic interest groups as well. Specifically, the goals of NGOs carry great importance. The stronger NGOs' ambition to influence UN policy-making, the more they rely on inside lobbying. We find this logic to apply among NGOs which are not membership organisations. When NGOs are dependent on membership contributions, their strategies must serve the dual objectives of securing organisational survival and gaining influence, which weakens the link between specific goals and strategies. A third important factor is the institutional access to decision-makers, where NGOs which consider themselves privileged in this regard are more likely to opt for an inside strategy than NGOs which see themselves as disadvantaged.

Third, our findings also provide evidence of important differences between NGOs in global governance and interest groups in domestic politics. Notably, an NGO's relative resource endowment does not appear to influence its choice of lobbying strategy in the UN. The absence of an effect of resources may be due to greater homogeneity in the population of NGOs mobilised internationally, given the costs of going global, or the irrelevance of certain resource-intense lobbying tactics in the international setting, among them, campaign contributions. This finding suggests that the importance of resources for lobbying strategies is contingent on the political context. For NGOs in global governance, the absolute level of resources is less determinative of their strategy choice than the means for securing those resources, where membership and non-membership organisations face distinctly different incentives. 


\section{References}

Baumgartner, F. R. and Leech, B. L. (1998) Basic interests. Princeton, NJ: Princeton University Press.

Betsill, M. M. and Corell, E. (2008) NGO diplomacy: the influence of nongovernmental organizations in international environmental negotiations. Cambridge, MA: MIT Press.

Beyers, J. (2004) 'Voice and access: political practices of European interest associations', European Union Politics, 5, 211-240.

Binderkrantz, A., (2005) 'Interest group strategies: navigating between privileged access and strategies of pressure', Political Studies, 53, 694-715.

Binderkrantz, A., (2008) 'Different groups, different strategies: how interest groups pursue their political ambitions', Scandinavian Political Studies, 31, 173-200.

Bloodgood, E. (2010) 'The interest group analogy: international non-governmental advocacy organizations in international politics', Review of International Studies, 37, 93-120.

Bob, C. (2009) The international struggle for new human rights. Philadelphia: University of Pennsylvania Press.

Carpenter, R. C. (2011) 'Vetting the advocacy agenda: network centrality and the paradox of weapons systems', International Organization, 65, 69-102.

Cooley, A. and Ron, J. (2002) 'The NGO scramble: organizational insecurity and the political economy of transnational action', International Security, 27, 5-39.

Della Porta, D. and Tarrow. S. (eds.) (2005) Transnational protest and global activism. Lanham, MD: Rowman and Littlefield.

Dür, A. and Mateo, G. (2013) 'Gaining access or going public? Interest group strategies in five European countries', European Journal of Political Research, 52, 660-686. 
European Union (EU) (2015) Transparency register. Available from: http://ec.europa.eu/transparencyregister/public/homePage.do [Accessed 18 January 2016].

Friedman, E. J., Hochstetler, K. and Clark, A. M. (2005) Sovereignty, Democracy and Global Civil Society - State-Society Relations at UN World Conferences. New York: State University of New York Press.

Grant, W. (2000) Pressure groups and British politics. London: Macmillan.

Guldbrandsen, L. and Andresen, S. (2004) 'NGO influence in the implementation of the Kyoto protocol: compliance, flexibility mechanisms, and sinks', Global Environmental Politics, 4, 54-75.

Guttman, L. (1954) 'Some necessary conditions for common-factor analysis', Psychometrika, 19, 149-161.

Hadden, J. (2015) Networks in contention. The divisive politics of climate change. Cambridge: Cambridge University Press.

Hanegraaff, M., Beyers, J. and De Bruycker, I. (2016) 'Balancing inside and outside lobbying: The political strategies of lobbyists at global diplomatic conferences', European Journal of Political Research, forthcoming.

Hanegraaff, M., Beyers, J. and Braun, C. (2011) 'Open the door to more of the same? The development of interest group representation at the WTO', World Trade Review, 10, $447-472$

Hansen, J. M. (1991) Gaining access: congress and the farm lobby, 1919-1981. Chicago, IL: University of Chicago Press.

Kahn, S. (2015) Mapping, Assessment and Review the Laws and Policies on Child Labour. Available from: http://www.csid-bd.com/research/Mapping\%20Assessment $\% 20$ and\%20Review.pdf [Accessed 18 October 2016]. 
Keck, M. E. and Sikkink, K. (1998) Activists beyond borders: advocacy networks in international politics. Ithaca: Cornell University Press.

Kline, P. (1994) An easy guide to factor analysis. New York, NY: Routledge.

Klüver, H. (2012) 'Informational lobbying in the European Union: The effect of organisational characteristics', West European Politics, 35, 491-510.

Kollman, K. (1998) Outside lobbying: public opinion and interest group strategies. Princeton: Princeton University Press.

Kriesi, H., Tresch, A. and Jochum, M. (2007) 'Going public in the European Union', Comparative Political Studies, 40, 48-73.

Lowi, T. J. (1964) 'American business, public policy, case-studies, and political theory', World Politics, 16, 667-715.

Martin, L. L. (2000) Democratic commitments: legislatures and international cooperation. Princeton: Princeton University Press.

Martin, L. L. and Simmons, B. A. (2012) 'International organizations and institutions.' In Handbook of International Relations, edited by Carlsnaes, W., Risse, T. and Simmons, B. A., 326-52. London: Sage.

Mitchell, G. E. and Schmitz, H. (2014) 'Principled instrumentalism: A theory of transnational NGO behavior', Review of International Studies, 40, 487-504.

O’Brien, R., Goetz, A. M., Scholte, J. A. and Williams, M. (2000) Contesting global governance: multilateral economic institutions and global social movements. Cambridge: Cambridge University Press.

Prakash, A. and Gugerty, M. K. (eds.) (2010) Advocacy organizations and collective action. Cambridge: Cambridge University Press.

Putnam, R. D. (1988) 'Diplomacy and domestic politics: the logic of two-level games', International Organization, 42, 427-460. 
Risse, T. (2012) 'Transnational actors and world politics', in W. Carlsnaes, T. Risse and B. A. Simmons (eds.), Handbook of International Relations. London: Sage.

Rittberger, V., Zangl, B. and Kruck, A. (2012) International Organization. $2^{\text {nd }}$ edition. Basingstoke: Palgrave Macmillan.

Rubin, D. B. (1976) 'Inference and missing data', Biometrika, 63, 581-592.

Schlozman, K. L. and Tierney, J. T. (1986) Organized interests and American democracy. New York: Harper and Row.

Schmitter, P. C. and Lembruch, G. (Eds.) (1979) Trends toward corporatist intermediation. London: Sage.

Stroup, S. S. and Murdie, A. (2012) 'There's no place like home: explaining international NGO advocacy', Review of International Organizations, 7, 425-448.

Tallberg, J., Sommerer, T., Squatrito, T., \& Jönsson, C. (2013). The opening up of international organizations: transnational access in global governance. Cambridge: Cambridge University Press.

Tallberg, J., Dellmuth, L. M., Duit, A., \& Agné, H. (2015). 'NGO influence in international organizations: information, access, and exchange', British Journal of Political Science, online first.

Thomson, G. H. (1951) The factorial analysis of human ability. London: University of London Press.

Tomz, M., Wittenberg, J. and King, G. (2003) Clarify: software for interpreting and presenting statistical results. Version 2.1, January 5. Available from: http://gking.harvard.edu/ [Accessed 18 January 2016].

Uhre, A. N. (2014) 'Exploring the diversity of transnational actors in global environmental governance', Interest Groups \& Advocacy, 3, 59-78. 
Union of International Associations. (2011) Yearbook of International Organizations Online. Available from: at: http://www.uia.be/yearbook-international-organizations-online [Accessed 18 January 2016].

United Nations (UN) (2011) Integrated civil society organizations system. Available from: http://esango.un.org/ [Accessed 18 January 2016].

United Nations (UN) (2015) Basic facts about ECOSOC status. Available from: http://csonet.org/index.php?menu=14 [Accessed 18 January 2016].

United Nations Development Programme (UNDP) (2014) Human development report. Available from: http://hdr.undp.org/ [Accessed 18 January 2016].

Walker, J. (1983) The origins and maintenance of interest groups in America. American Political Science Review, 77, 390-406.

World Bank (2015) The World Bank and civil society. Available from: http://web.worldbank.org/WBSITE/EXTERNAL/TOPICS/CSO/0,,pagePK:220469 the SitePK:228717,00.html [Accessed 18 January 2016]. 


\section{Appendix}

\section{Cited Semi-Structured Interviews}

1: UN official, Department of Economic and Social Affairs, UN Secretariat, July 2, 2012.

2: UN official, High Level Committee on Programmes, UN Secretariat, July 23, 2012.

3: UN official, Press and External Relations Service, UN Secretariat, August 7, 2012.

4: Member state representative, Permanent Mission of Finland to the UN, July 9, 2012.

5: Member state representative, Permanent Mission of the United States to the UN, July 19, 2012.

6: Member state representative, Permanent Mission of the Netherlands to the UN, July 16, 2012 .

7: UN official, Office for ECOSOC Support and Coordination, UN Secretariat, July 10, 2012.

8: UN official, Office for ECOSOC Support and Coordination, UN Secretariat, July 11, 2012.

9: UN official, Department of Economic and Social Affairs, UN Secretariat, July 11, 2012.

10: UN official, UN Permanent Forum on Indigenous Issues, UN Secretariat, August 3, 2012.

11: Member state representative, Permanent Mission of Switzerland to the UN, August 8, 2012. 


\section{Tables and Figures}

Table 1 Factor analysis of advocacy strategies

\begin{tabular}{lcc}
\hline Variables & $\begin{array}{c}\text { Factor 1 } \\
\text { ('outside strategy') }\end{array}$ & $\begin{array}{c}\text { Factor 2 } \\
\text { ('inside strategy') }\end{array}$ \\
\hline Mobilising public opinion through news media & $\mathbf{0 . 8 3 7 7}$ & 0.0448 \\
Mobilising public opinion through social media & $\mathbf{0 . 8 0 5 5}$ & 0.0441 \\
Mobilising public opinion through campaigns, protests and events & $\mathbf{0 . 8 3 6 2}$ & -0.0489 \\
Providing policy information or expertise & 0.0020 & $\mathbf{0 . 7 8 5 6}$ \\
Providing financial or material resources & 0.1548 & $\mathbf{0 . 6 6 7 9}$ \\
Providing information on represented views and needs of groups & 0.0064 & $\mathbf{0 . 8 1 1 1}$ \\
Interacting with UN or state representatives & -0.0590 & $\mathbf{0 . 7 7 8 5}$ \\
& & 1.127 \\
Eigenvalue & 3.372 & $16.11 \%$ \\
\hline
\end{tabular}

Note: $N=198$. The figures are factor loadings from a factor analysis based on principal components extraction, assuming that the communality estimate for a variable is 1 . Factor loadings refer to the correlation between the variables and the factor and, hence, express how much a variable has contributed to a factor (Kline, 1994). Variables loading strongly on a factor are marked in bold. Loadings are rotated so that the factors are allowed to correlate using promax rotation.

Table 2 NGO goals in the UN

\begin{tabular}{lccc}
\hline & $\begin{array}{c}\text { Membership } \\
\text { organisations } \\
\text { (often or very often) }\end{array}$ & $\begin{array}{c}\text { Non-membership } \\
\text { organisations } \\
\text { (often or very often) }\end{array}$ & $\begin{array}{c}\text { All organisations } \\
\text { (often or very often) }\end{array}$ \\
\hline Seek influence & $\begin{array}{l}48 \% \\
(63 \text { of } 130)\end{array}$ & $\begin{array}{c}52 \% \\
(42 \text { of } 80)\end{array}$ & $\begin{array}{c}50 \% \\
(105 \text { of } 210)\end{array}$ \\
$\begin{array}{l}\text { Enhance visibility of } \\
\text { organisation }\end{array}$ & $63 \%$ & $60 \%$ & $62 \%$ \\
Collect information & $(81$ of 129$)$ & $(49$ of 82$)$ & $(130$ of 211$)$ \\
& $(96$ of 133$)$ & $80 \%$ & $75 \%$ \\
Attract funds & $21 \%$ & $(68$ of 85$)$ & $(164$ of 218$)$ \\
& $(27$ of 128$)$ & $19 \%$ & $20 \%$ \\
\end{tabular}

Note: Question wording: How often does your organisation pursue the following goals in the $\{\mathrm{IO}$ body $\}$ ? "Never"; "Rarely"; "Often"; "Very often"; "Don't know". 
Table 3 Regression analysis of strategy choice

\begin{tabular}{lcccc}
\hline & $(1)$ & $(2)$ & $(3)$ & $(4)$ \\
\hline Seeking influence & $0.327^{* * *}$ & $0.247^{* * *}$ & $0.526^{* * *}$ & $0.470^{* * *}$ \\
& $(0.092)$ & $(0.088)$ & $(0.144)$ & $(0.135)$ \\
Membership organisation & & -0.216 & 0.668 & 0.726 \\
& & $(0.149)$ & $(0.489)$ & $(0.454)$ \\
Influence * membership & & $-0.353^{*}$ & $-0.366^{* *}$ \\
& & & $(0.186)$ & $(0.175)$ \\
Resources & & & 0.007 \\
& & $(0.039)$ & & $(0.039)$ \\
Access & $0.184 * * *$ & & $0.189 * * *$ \\
& & $(0.068)$ & & $(0.066)$ \\
Regulatory policy & & 0.099 & & 0.080 \\
& & $(0.151)$ & & $(0.152)$ \\
Constant & & & \\
& $-0.794 * * *$ & $-1.056 * * *$ & $-1.174 * * *$ & $-1.650 * * *$ \\
Adj. $R^{2}$ & $(0.228)$ & $(0.334)$ & $(0.407)$ & $(0.414)$ \\
\hline
\end{tabular}

Note: $N=190$. Figures in the table are unstandardised coefficients from OLS regression analyses using weighted data. Significance levels: ${ }^{*} \mathrm{p}<.10,{ }^{* *} \mathrm{p}<.05,{ }^{* *} \mathrm{p}<.01$

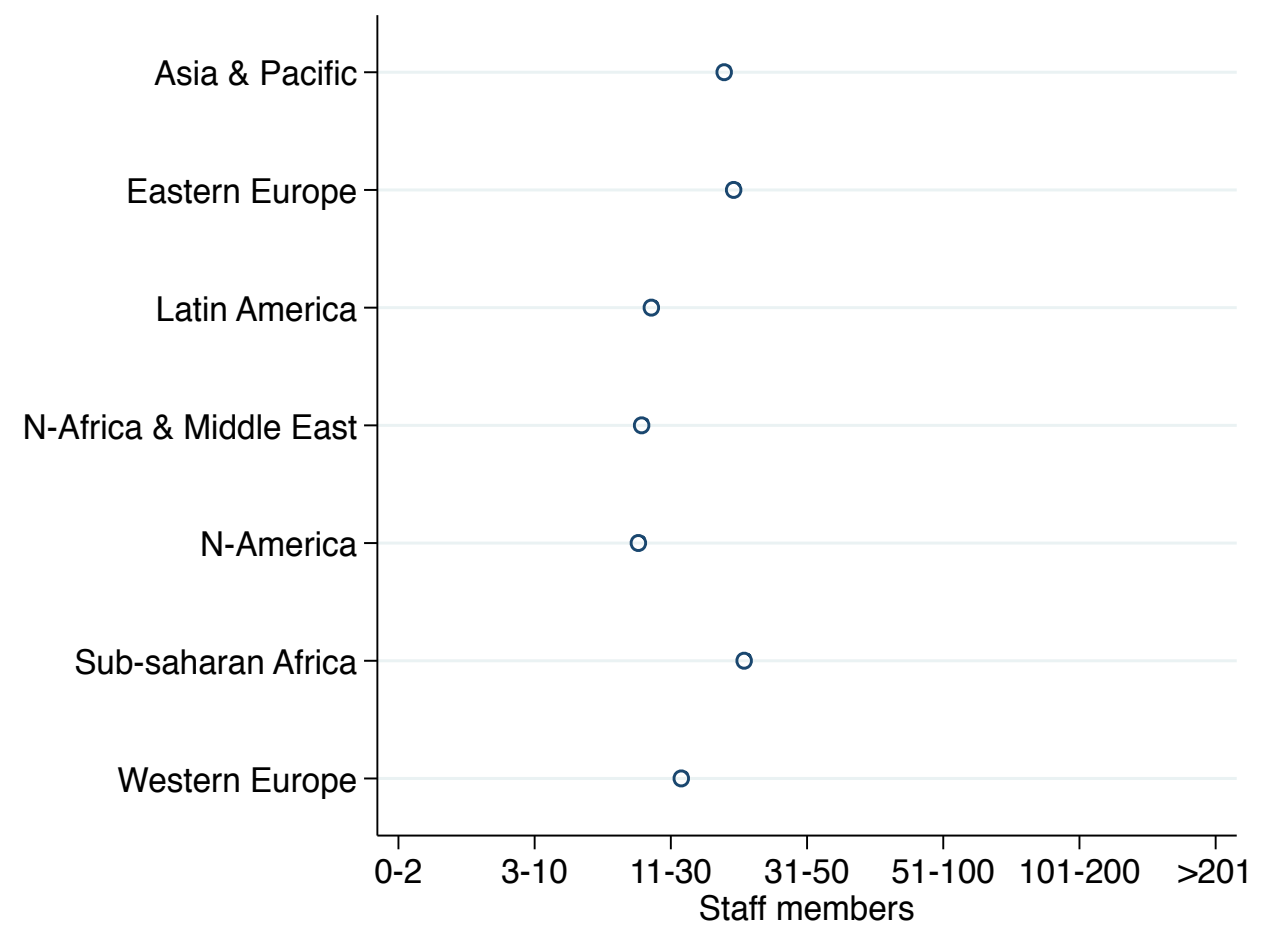

Fig. 1 Resource endowment of NGOs in the sample.

Note: Average resource endowment of NGOs with headquarters in different world regions. $N=190$. Question wording: 'How many permanent staff members does your organisation employ on a full-time basis?' Due to the potential sensitivity of this question, we provided seven substantive answer categories $(0-2,3-10,11-30,31-50$, 51-100, 101-200, over 201) and a 'don't know' option. 


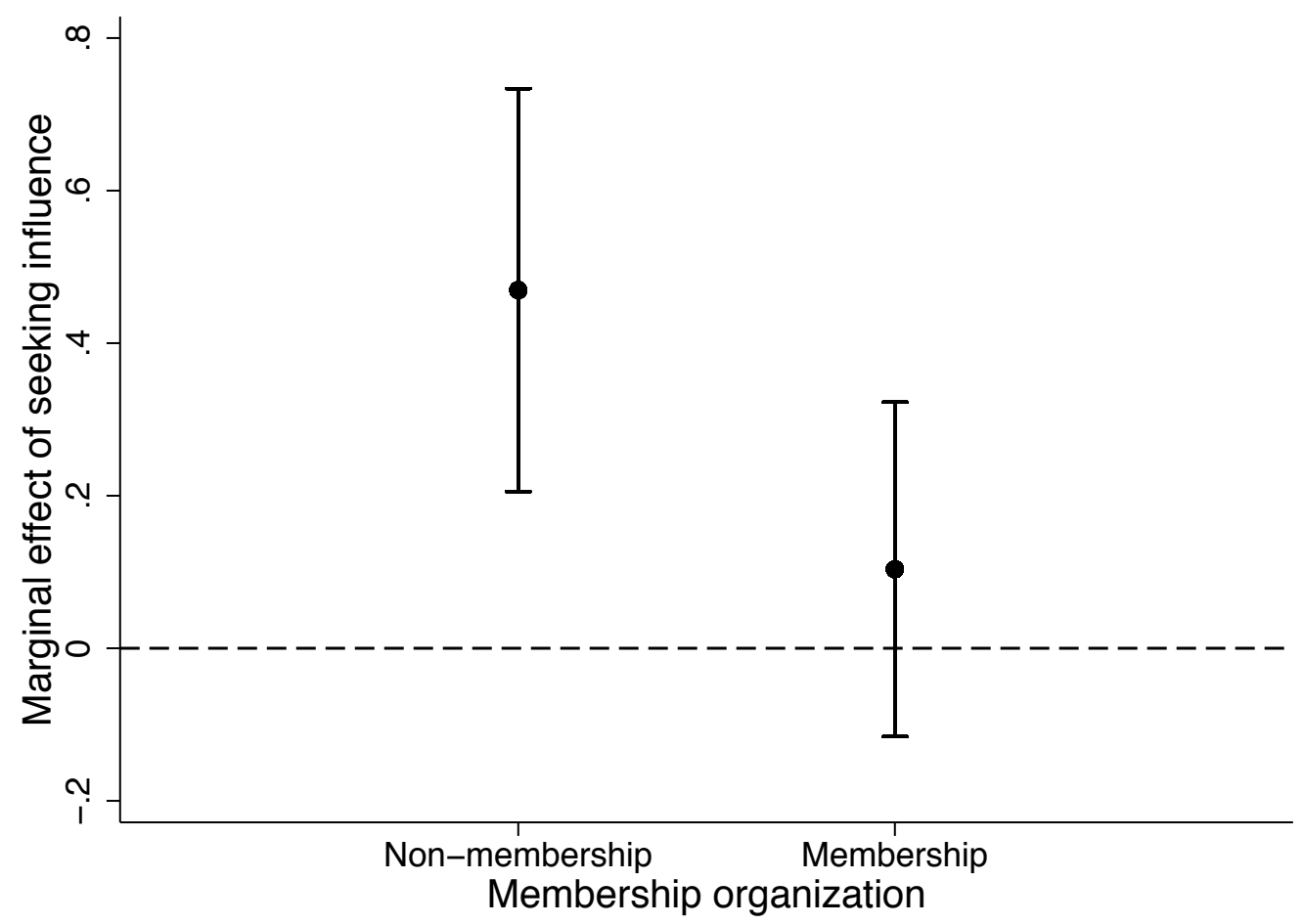

Fig. 2 Moderating effect of organisational structure.

Note: Based on the estimations from model 4 in Table 3. 